\title{
APORTACIONES DRAMATÚRGICAS \\ DE J. L. LÓPEZ PINILLOS. \\ LA TRASCENDENCIA DE LA DIMENSIÓN PRAGMÁTICA
}

\author{
DRAMATURGIC CONTRIBUTIONS OF J. L. LÓPEZ PINILLOS. \\ THE TRANSCENDENCE OF THE PRAGMATIC DIMENSION
}

\author{
Sergio PRATS MARTÍN \\ Instituto Julio Antonio (Tarragona) \\ sprats7@xtec.cat
}

Resumen: En ocasiones, atribuimos arbitrariamente triunfos de tendencias o géneros literarios a ciertos escritores sin darnos cuenta de que ha sido un vasto elenco el que ha contribuido a la germinación, preservación y transformación del mismo. Así terminamos aceptando ciertos encorsetamientos que simplifican y oscurecen la realidad de géneros como el exitoso drama rural. El análisis semiótico de Esclavitud (1918), al ser un método integral del artefacto dramático, nos permite ver hasta qué punto López Pinillos, con esta obra paradigmática, transforma el ruralismo exitosamente. Resulta imprescindible, empero, al ser obra de su tiempo, atender especialmente las coordenadas pragmáticas de su estreno.

Palabras clave: López Pinillos (Parmeno). Esclavitud. Ruralismo desagradable. Semiótica teatral. Pragmática.

Abstract: Sometimes, we arbitrarily attribute triumphs of one tendency or literary genre to certain writers without realizing that it has been an 
extensive list the one that has contributed to its germination, preservation and transformation. Thus, we end up accepting some straight-jacketing which simplifies and darkens the reality of genres like the successful rural drama. The semiotic analysis of Esclavitud (1918), being a comprehensive method of the dramatic artifact, allows us to see how López Pinillos successfully transforms ruralism with this paradigmatic work. However, since it is a work of its time, it is essential to especially meet the pragmatic coordinates of its premiere.

Key Words: López Pinillos (Parmeno). Esclavitud. Unpleasant ruralism. Semiotics of Theatre and Drama. Pragmatic.

\section{INTRODUCCIÓN. LA "POÉTICA POTENCIAL" DRAMÁTICA DE J. L. LÓPEZ PINILLOS}

La eclosión de exitosos géneros dramáticos viene de las aportaciones que se han ido jalonando paulatina y diacrónicamente. Sin embargo, el estudio de estos sistemas ofrece ciertos arbitrios que oscurecen la auténtica aportación de algunos de esos eslabones.

En este sentido, nos parece oportuno apuntar cuáles son los factores que deben tenerse en cuenta para comprender bien las coordenadas productivas de las exitosas dramaturgias de ambientación rural de principios de siglo XX, pues, de ellas, en el mejor de los casos, solo conservamos los textos literarios, a los cuales hoy se confiere todo ese valor que, en su tiempo, en realidad, no tuvieron, al ser concebidos como textos efímeros para la posible cristalización escénica: sus referentes, a veces, son tan inmediatos que obligan a entenderse como obras de su tiempo, por lo que su faceta escénica cobra casi más valor que la literaria.

En este sentido, nuestra investigación ha pretendido analizar una obra que nos parece crucial en la historia del género dramático de ambientación rural: Esclavitud (1918), de J. L. López Pinillos; pero para entender tanto su finalidad y las claves de su éxito, como las aportaciones, lo genuino y perdurable del dramaturgo, es necesario analizar la pieza con un método tan integral como el semiótico, ya que, además de inventariar los signos y entender su proyección semántica, permite poner en relación el texto y cotexto con su contexto. Dicho de otro modo, para que el lector actual 
pudiera traspasar lo anacrónico de su teatro, es necesario que entienda esa propedéutica teatral; como producto escénico regeneracionista de consumo y engendrado ad hoc para la representación.

No se pretende, pues, verter simplemente los resultados obtenidos del análisis semiótico de la obra que, en cualquier caso, pueden consultarse en el trabajo Una nueva mirada al teatro de J. Luis López Pinillos ("Parmeno"). Análisis del drama "Esclavitud" (1918) (2016). El principal objetivo es, a partir del análisis semiótico, explorar las claves (dimensión pragmática) para la correcta hermenéutica del drama y así, aprehender lo genuino del dramaturgo y sus aportaciones, que fueron en su tiempo enormemente ovacionadas. Por tanto, tras el examen del hecho teatral parmeniano del estreno de Esclavitud y teniendo en cuenta esas fuentes cruciales para la investigación teatral de principios de siglo como son las periodísticas, se rastrean las intenciones del autor, el papel conferido a la compañía, los elementos del orbe escénico, las expectativas tanto del autor como del público, crítica y empresarios, y finalmente, su acogida. Son, sin duda, claves para enjuiciar la obra como un eslabón importante de la evolución y transformación del drama rural español, y entendemos que solo de este modo, más allá de desempolvar el nombre del literato, conseguiremos calibrar cuánto distaba la aspiración, de sus verdaderos resultados; la originalidad y ulterior influencia... Dicho de otro modo, poder entender esa posible poética potencial a la que se refería José Carlos Mainer, necesaria para poder aspirar a integrar, en este caso, a López Pinillos dentro del presunto y presumible canon literario, pues la posible poética potencial propone siempre la "permanente renovación del 'canon' [...] que es, a la postre, el diálogo entre el presente y el pasado, entre la originalidad y la influencia, entre la aspiración y los resultados" (Mainer, 2000: 263).

\section{EL DRAMA RURAL. CONTEXTO Y CONFIGURACIÓN DE UN GÉNERO TEATRAL EXITOSO}

Sin duda, uno de los géneros dramáticos que triunfaron a principios del siglo XX, en parte aprovechando el rebufo realista de la segunda mitad del siglo XIX, fue el teatro de ambientación rural. Pedraza Jiménez estudia en El drama rural: metamorfosis de un género: la perspectiva española $y$ el contexto internacional (2011) el arranque del drama rural español 
con Feliu y Codina y la aportación catalana de dramaturgos como Àngel Guimerà. Asimismo, fue empapándose de tintes sociales con Joaquín Dicenta quien trazó cuadros verosímiles de los casi feudales campos españoles de la época de la Restauración para hilar una mesurada crítica: una diatriba que no sonrojase ni escandalizase en demasía a ese público histórico.

Por tanto, germinan y se transforman las propuestas estéticas, muchas de las cuales tienen ese verismo y ruralismo vertebrador de las comedias barrocas de comendadores.

Poco a poco, se daría un fuerte sincretismo al barajar ornamentos efectistas con lenguajes simbolistas y hasta dosis de sordidez naturalista para engalanar tramas cuya concomitancia fuese la tensión individual y la lucha casi patológica por preservar el honor individual, familiar o social zaherido, a veces mancillado por opresión y hasta por agresión física, psicológica y sexual. En definitiva, motivos perfectamente codificables en el lenguaje escénico y mensajes fácilmente extrapolables por parte del espectador histórico del artefacto dramático resultante.

El teatro madrileño del momento era, tal y como analiza César Oliva en "Teatro y sociedad en la España del siglo XX" (2001), un espectáculo de masas de primer orden y, en esos tiempos de éxodo rural, una propuesta de ocio tan aplaudida y seguida como los rentables espectáculos taurinos. Sin embargo, la competencia de esos otros entretenimientos, de entre los que destaca también el creciente fervor por el cinematógrafo, forzaba a los empresarios teatrales a buscar estrategias que garantizasen la ocupación del máximo número de localidades posibles. Por ello, además de por el encarecimiento de las puestas escénicas y las reivindicaciones del personal del teatro, solo se arriesgaban a invertir en aquellas producciones que cubrían las expectativas y gustos populares: presencia de flamantes actores en funciones de géneros consolidados y aplaudidos como los music-hall, tablaos, cuplés, sainetes líricos y zarzuelas. Por tanto, y en resumen, el teatro rentable de principios de siglo era convencional y distaba de propuestas innovadoras: los gustos del público burgués forzaban a apostar por un teatro no rupturista, fiel a los géneros en boga y funciones concebidas como coartadas para el lucimiento interpretativo de los actores de moda.

Con todo, el dramaturgo que anhelaba un hueco en las carteleras madrileñas debía, para ofrecer el mejor producto, aceptar las condiciones del momento, trazar obras pensando en quiénes iban a representarlas y 
medir constantemente el pulso tanto del insaciable público y de exigentes empresarios como de las solícitas compañías preparadas a renovar nuevos estrenos.

Quienes apostaron por este derrotero de convencionalidad debían respetar el canon establecido y, de algún modo, ser deudores de los dos tótems que aglutinaban mayor veneración. Nos referimos a José Echegaray y Jacinto Benavente, esas dos portentosas plumas cuyas labores fueron recompensadas con el galardón del Nobel en 1904 y 1922, respectivamente. Por estos, el tono del teatro convencional orbitó entre el refinamiento grandilocuente, efectista, moralizador y neorromántico, y el tono realista e irónico con una supremacía por ambientes burgueses.

En las posibles nuevas propuestas, por tanto, se debían medir bien las dosis ofrecidas al público -temáticas, estilísticas y escenográficaspara conseguir sus fines sin despertar la desidia del espectador, ese que, a fin de cuentas, podía llegar a soterrar su fama y, por ende, sus ingresos, su carrera y, en última instancia, sus posibles apuestas dramáticas más o menos innovadoras.

Pese a la dificultad, empero, hubo quien abrió una fina brecha en la convención y viró el género hacia un sello particular, transformándolo en un artilugio reivindicativo con calculada habilidad. Este es el caso de dramaturgos como José Luis López Pinillos (Parmeno), una de esas "variantes obsoletas del teatro de ambiente rural" (Pedraza Jiménez, 2001: 87) según algunos críticos, cuya obra, heredera de dramas sociales como Juan José (1985), de Dicenta, proporcionaron, en realidad, unas aportaciones más reveladoras de lo que se ha venido considerando.

\section{EL TEATRO PARMENIANO. DE LA ASPIRACIÓN A LA CONSAGRACIÓN}

J. L. López Pinillos (1875-1922) engruesa el tópico de artistas periféricos $^{1}$, como los hermanos Machado, Alejandro Sawa, Álvarez Quintero y Chaves Nogales, entre otros, que emigraron a la capital en busca de posibilidades y remuneración por su actividad literaria, al ser el Madrid de entonces un hervidero intelectual y un posible trampolín para la

1. Nació en una fonda sevillana, aunque estuvo muy vinculado a la ciudad de su madre: Castro del Río (Córdoba). 
notoriedad y reconocimiento.

Tras la muerte de su padre, el andaluz se dirigió al pulmón de esa España e inició un periplo de experiencias por rotativos como El Globo, España, Alma Española; redacciones donde conoció a buena parte de la intelectualidad del momento como los hermanos Baroja y J. Martínez Ruiz. La publicación de crónicas y artículos -además de tres novelas ${ }^{2}$ y numerosos relatos cortos- le fue permitiendo la resonancia de su nombre $\mathrm{y}$, por ende, la consolidación de su fama.

Sin embargo, tal y como señala Awono Onana en El teatro de López Pinillos, Parmeno (2004), un punto de inflexión importante en su carrera se produjo en 1918, aunque el especialista no ahonde -según nuestro parecer-en los porqués. En realidad, fue el año del advenimiento teatral; se produjo cierta concatenación de hechos que permitieron que Parmeno no solo correspondiese al nombre de un narrador y gacetero progresista, sino también al pseudónimo de un sesudo dramaturgo que estaba obteniendo -no sin infatigable testarudez y dificultad, tal y como reconoció en la crónica "Adiós tradición" (López Pinillos, 1908: 7)- ahuecarse en las carteleras madrileñas. Fin de esa etapa periodística y narrativa, iniciada al pisar Madrid para ver representada su primera obra: el drama urbano El vencedor de sí mismo, estrenado en el Español, el 1 de abril de 1900. Lapso duro, como decíamos, ya que, aunque la crítica elogió la obra hasta el punto de poder fantasear una prometedora carrera inminente, recibió un lapo de realidad, al entender la dificultad de posibilidades dramáticas sin el socorro de notorios literatos y críticos teatrales como Francisco F. Villegas (Zeda): efectivamente, no pudo ver representada su segunda obra hasta una década después (Hacia la dicha, 1910), verdadero inicio de experimentación y jalonamiento de triunfos hasta su consagración y cenit.

Sin embargo, lejos del desconsuelo, su autonomía teatral terminó sobreponiéndose gracias a su obstinación: al analizar las propuestas dramáticas por que apostaban los empresarios, el calado de los actores, la repercusión de los géneros y temas, y, por encima de todo, o quizá como catalizador de ello, al tomar infatigablemente el pulso al público consumidor. De este modo y siguiendo las tendencias remuneradas, pudo ofrecer, entre no pocos loores, ese sello individual que bien podríamos reconocer como parmeniano.

2. Doña Mesalina (1910), Las águilas (de la vida del toreo) (1911) y El luchador (1916). 
De hecho, su actividad dramatúrgica resultó frenética, ya que vio la posibilidad de ver representadas en Madrid cuatro obras a lo largo de todo ese 1918: A tiro limpio (estrenado el 14 de enero en el Infanta Isabel); Los senderos del mal (el 30 de marzo en el Lara); Las alas (el 19 de octubre en el Cervantes), y Esclavitud (el 11 de diciembre en el Centro).

Esta última, como paradigmática de su producción, podría encorsetarse, junto con las propuestas teatrales de Francisco de Viu, dentro de una revolucionaria dramática rural con tintes sociales y denominador reformista:

Tendencia que subraya el papel del pueblo en la escena y donde las diferencias entre las clases sociales están muy acentuadas. [...] Así, los dramaturgos no solo tratarán de convencer racionalmente al público acerca de la bondad de ciertas ideas progresistas sino que, además, presentarán personajes y situaciones melodramáticas que apelen al sentimiento y a las emociones. Esta exageración de los elementos sentimentales y patéticos busca provocar la complicidad del espectador identificado con los personajes (Almarcha Romero, 2015: 165).

Una tendencia en cuyo crisol sistémico ardería lo reivindicativo y reformista:

1. La aguda crisis española, tanto política como económica, [...] la situación catastrófica del campesinado y de la agricultura hacen que una serie de hombres adopten una postura crítica que denuncia la insuficiencia de unas estructuras politicas caducas.

2. El reformismo es la posición que adopta un considerable número de intelectuales españoles, de ideología indefinida, liberal, de izquierda republicana. Estos hombres tienen una dolorosa conciencia del atraso cultural y económico de España y adoptan la decisión de contribuir con sus obras a superarlo.

3. Les preocupa la realidad social española. No es posible resolver la situación política sin una previa reforma social, 
basada en una reestructuración de la propiedad agraria. Les preocupa la incultura del pueblo español, sus vicios, su mentalidad. Y desean contribuir al cambio, a la evolución. 4. Las figuras que adoptan esta posición son: Joaquín Riera i Bertran, J. Capella, Ramón i Vidalés, Torrendell, Josep Pous i Pages, Santiago Rusynol, Puig i Ferreter, López Pinillos, Federico Oliver, Francisco de Viu (Castellón, 1994: 139-140).

En todo caso, los tintes desagradables fruto de su temple displicente y la visión cruda de la realidad pivotan como elementos que singularizaron las aportaciones de López Pinillos, perfectamente reconocibles en Esclavitud.

\section{LA OBRA PARADIGMÁTICA. ESCLAVITUD (1918)}

En referencias fortuitas al autor, publicadas en artículos o epígrafes fortuitos de algún manual, se enumera la producción parmeniana resaltando títulos narrativos y dramáticos, entre los que, a veces, no figura el de Esclavitud. No obstante, pese al papel tibio de la obra en esos recordatorios, nos parece oportuno reivindicarla dentro del por ya olvidado autor.

Con el drama rural Esclavitud (1918), Parmeno consiguió apuntalar su idea estética y concepción dramática, ese ruralismo desagradable con que había ido experimentado, por ejemplo, en El Pantano (1913) y que, tras el éxito de Esclavitud, no atenuaría en las siguientes: "'Esclavitud' quedará, no os quepa duda" (Carretero Novillo, 1918b: 15).

El éxito de aforo en el estreno dilató la temporada con representaciones diarias $^{3}$ hasta enero $y$, por el rédito recaudatorio, acarició esa meta que había estado anhelando desde que llegara a Madrid dos décadas atrás: la exclusiva dedicación teatral. Un advenimiento por otras muchas condecoraciones que la obra le canjeó como el galardón "Premio Piquer", concedido por la Real Academia Española a la mejor obra dramática

3. Se representó todas las noches a las 22.00 h o 22.15 h, según el día, a excepción del jueves 12 de diciembre, que se representó por la tarde, al estar programada la función El alcalde de Zalamea, de Calderón de la Barca, con fines benéficos. 
del año; un homenaje en el Hotel de Ritz de Madrid'; la concesión de la Medalla Alfonso XII; una composición poética del bonaerense anarquista Alberto Ghirlado ${ }^{5}$; reposiciones durante toda la primera mitad de siglo por España $^{6}$, y la traducción de la obra al catalán (1933) por parte de Josep Amich i Bert (Amichatis).

\section{PARÁMETROS PARA EL ANÁLISIS DEL HECHO TEATRAL}

\subsection{La semiótica teatral, como método operante}

Con el fin de explorar la obra desde todas esas perspectivas posibles, empleamos un método analítico -totalmente operativo en la actualidad-, que permite explorar todos los recovecos del hecho teatral, al concebir el artefacto dramático como producto lingüístico y escénico ${ }^{7}$, llegando incluso a calibrar la performance como idiosincrático del género. Por tanto, se trata de un proceso de comunicación complejo donde figuran, según los momentos, distintos emisores y receptores.

Para la comprensión dramática, el semiológico decodifica esa multiplicidad de códigos y signos interrelacionados (lingüísticos y no verbales), y los disecciona teniendo en cuenta la relación que proponía Peirce: (A) significante, (B) significado y (C) referente. De este vínculo, se explica que tres sean los niveles analíticos del método, "aunque artificialmente y solo con justificación epistemológica en nivel sintáctico, semántico y pragmático" (Tordera, 1980: 177).

Por ello, hemos establecido los sistemas y la relación entre signos en el nivel morfosintáctico (relaciones A-B); la significación de los mismos en

4. El domingo 29 de diciembre en el Ritz de Madrid se celebró un emotivo y multitudinario homenaje dedicado al autor y actor principal, como reconocimiento tras el éxito de la obra.

5. Poema titulado "El drama" leído por Manuel Machado en la comida homenaje en el Ritz, cuyos versos pueden leerse en El Fígaro (30 de diciembre de 1918: 10).

6. Gracias a los carteles de que disponen los archivos de teatros, la Biblioteca de la Fundación Juan March y el Centro de Documentación Teatral, se pueden seguir muchas de las reposiciones. Por ejemplo, el 3 de diciembre de 1912 se representó en Teatro Rosalía de Castro (La Coruña); el 14 de enero de 1928, en el Teatro Principal de León, y el 5 de febrero, en el de Zaragoza; el 15 de enero de 1932, en el Teatro Español (Madrid); el 15 de marzo, en el Teatro Nuevo (Barcelona); el 25 de junio de 1946, en el Romea...

7. El perfeccionamiento del método (gracias, en buena parte, a las TIC) permite vislumbrar lejanamente aquellos comentarios de Urrutia y Serpieri, quienes coincidían en señalar la imposibilidad analítica de la representación escénica. 
el nivel semántico (relación B-C), hasta llegar a su proyección extraliteraria, en el nivel pragmático (relación entre signos y sus coordenadas históricosociales).

\subsection{Fuentes para el análisis de lo literario y espectacular}

Una vez referido el marco metodológico, resumimos algunas consideraciones previas sobre el corpus con que se ha trabajado. Cuando no se dispone de registro audiovisual de un estreno, el semiólogo puede hallarse desamparado y recuerda que "uno de los escollos más graves del análisis teatral [es] el hecho de que la representación teatral aunque debe sentido último a la obra dramática es irrepetible y fugaz" (Tordera, 1980: 177).

Esclavitud es una de esas piezas de principios del siglo XX de la que se disponen escasos materiales visuales que limitan la praxis analítica de su performance. Para ello, empero, definimos como corpus aquellos signos extraídos tanto del texto literario como de las fuentes periodísticas, ya que estas aportan un importante caudal de datos, como demuestra J. Almarcha Romero en "Algunas fuentes periodísticas para el estudio del teatro de Francisco Viu” (2015: 163-178).

Concretando más, para el análisis diegético, se ha tomado la $1 .{ }^{\text {a }}$ edición de la obra, texto editado por Renacimiento (1918) e impreso en los talleres de Juan Pueyo (Luna, 29) de Madrid. Además, este también se ha tenido en cuenta para valorar parte de la funcionalidad mimética de los elementos teatrales, ya que, como afirmaba Gutiérrez Flórez, para hallar la dramaticidad (lo verbal y no verbal), "puede tomarse el texto como objeto base de análisis, ya que contiene, potencialmente, todos los signos operantes en la representación (actualización del texto)" (Gutiérrez Flórez, 1989: 91-92).

No obstante, para examinar la escenificación y éxito del estreno del drama, se ha seguido la información de las secciones teatrales de distintas cabeceras madrileñas del momento, ya que ofrecen noticias, descripciones, valoraciones y hasta materiales visuales que facilitan la comprensión de la codificación de vestimenta, peinado, decorado y demás utilería. Con todo, nos disponemos a volcar los resultados y conclusiones más significativos tras el análisis semiótico. 


\section{OBSERVACIONES SIGNIFICATIVAS TRAS EL ANÁLISIS}

Esclavitud, por sus características sistémicas, es un drama social de ambientación rural, perfectamente diseñado para su representación; López Pinillos puso atención a una red de sistemas de signos semióticos que fácilmente permitiesen tanto la identificación del género, como la extrapolación regeneracionista; evidenciar una realidad -retratada con crueldad y patetismo-, a fin de agitar las conciencias del espectador y, por ende, conseguir una actitud combativa contra el sistema sociopolítico, económico y, sobre todo, moral de la Restauración. A través de un género que estaba en boga, se pretendió inocular esa acción necesaria -y hasta entonces ausente- a la que se refirieron autores como Joaquín Costa para erradicar los males nacionales, en pro de una "España Nueva".

Así, la labor de López Pinillos se enmarca en el credo regeneracionista que ambicionó combatir los efectos del turnismo partidista, cuyas consecuencias más visibles se traslucían en la que sería la principal motivación espacial dramática: los campos españoles. Para batallarlas mediante la estética realista-genuinamente tratada con dosis de naturalismo desgarrador-, intentó trasladar al lenguaje escénico arquetipos que el espectador reconociese fácilmente. De este modo, puede entenderse este drama como un buen instrumento para la movilización y el cambio, tal y como estimaba conveniente Ramiro de Maeztu: es necesario que el pueblo se "organice en partido o en partidos radicales [...]. Mas para hacer que el pueblo se organice hay que 'meter ruido, charlar, discutir'" (Awono, 2004: 52).

En cierto modo, pues, existe cierta epistemología teatral que pasa por la implicación del autor tanto o más en el texto espectacular, que en el texto literario, al considerar la representación el momento mágico "cuando el actor y el espectador se encuentran" (Tordera, 1980: 166) en una comunicación irrepetible; dicho de otro modo, el momento donde se consiguen los verdaderos efectos psíquicos del espectador al "acercarse con la mente a la situación que le va a presentar la obra" (Sito Alba, 1987: 181).

Parmeno calculó una obra cuyos signos orbitasen para ese momento mágico de la representación y se comprometió en las directrices escénicas. Por tanto, para su correcta hermenéutica, es necesaria esa clave que, de algún modo, ya se argüía desde las páginas de El Fígaro: "dramaturgo, 
literato y pensador caminan unidos, sin ninguno sobrepujar a otro" (Carretero Novillo, 1918b: 16).

Esclavitud trata el problema de la situación rural de los pueblos españoles, recreando un argumento intrahistórico hábilmente calibrado, empero, para la fácil extrapolación metonímica y simbólica. Acorde con la información espacial introductoria -"Puede la acción desarrollarse en cualquier pueblo de España" (López Pinillos, 1918: 9)-, se retrata un pueblo agrario que bien puede ser reflejo de cualquiera: vetusto, misógino, analfabeto, abúlico, y con costumbres tan arraigadas que no permiten ni el progreso ni la felicidad. Una inoperatividad sistémica interesante para el cacique (Antonio Venegas) y aceptada con resignación por sus siervos: "Sacris: Ea, a no cavilar, que las cosas son como Dios quiere que sean y na se remedia con cavilaciones" (López Pinillos, 1918: 54).

Con ciertas reminiscencias del El señor feudal (1896) de J. Dicenta, el drama se detiene en las consecuencias del caciquismo sufridas por la familia Govanes, quien sirve al autócrata en su morada; una situación a la que se ha llegado -según se va descubriendo- a través del sentimiento de culpabilidad y deuda -"Don Pedro: Para el mundo, soy yo el deudor" (López Pinillos, 1918: 16) - con ese autócrata agresivo, adinerado y aparentemente creyente y culto $^{8}$; en definitiva, bazas con que somete al vulgo y legitima su poder: "Esclavos del cacique son los vecinos de un pueblo, ¿de Castilla, de Andalucía?, es igual, de España, sometidos al amo porque tiene dinero e influencia política y habilidad para triunfar" (Brun, 1919: 80). Una potestad aparentemente conferida democráticamente a través de las votaciones referidas anafóricamente, aunque enseguida se comprenden amañadas, fruto de chantajes y amenazas.

Difícil resulta a la familia Govanes virar la situación por las deudas y abusos deshonrosos, lo que desencadena una realidad enquistadamente atormentada y una parálisis solo soportable con la ingesta alcohólica: "Sacris. Hay que rematar en bebedor con objeto de no aburrirse ni preocuparse mucho...Riendo. To el mundo bebe: unos pa ahogar en vino las penas, y otros pa emborrachar el hambre" (López Pinillos, 1918: 54).

Solo la llegada de Pedro Luis Govanes supone una posibilidad de cambio al convertirse en agitador de conciencias del soporífero pueblo.

8. Exhibe en la galería de su casa, además de pinturas con motivos religiosos (simbólica anunciación), títulos académicos de cursos finalizados. 
Llegado de un simbólico Buenos Aires ${ }^{9}$, lugar donde trabajó duramente y conoció otros sistemas diferentes al estercolero rural de donde emigró a los diez años, observamos a un hombre luchador, próspero, con buena dicción que pronto descubrirá los tapujos y la esclavitud de sus familiares. Su lucha -como la de Parmeno ${ }^{10}$ con el espectador-será la de convencer del sinsentido del status quo.

Sin embargo, acorde quizá con el pesimismo parmeniano, un halo trágico teñirá la obra cuando, decididos a actuar contra el tirano, a quien mata accidentalmente este forastero con un furtivo disparo, se revela el destino trágico de la familia - metonímicamente del pueblo y de la nación-: el padre hiere adventicia y fatídicamente a su hija Julia. Por tanto, se trata de un final abierto poco esperanzador, si el espectador infiere que la muerte de Don Antonio no supone el final del caciquismo, ya que Sacris, amigo del protagonista, podría ostentar ese cargo por el cual conspiraba antes de iniciarse la trama mimética. En este caso, lejos de atenuarse la situación, se agravaría, al ser este un tipo más inculto (reflejado en su dicción pobre y vulgarismos cometidos) y con unos valores más rancios y arraigados. En cualquier caso, no se recoge la rebelión de los esclavos como en las obras de comendadores, sino de la familia Govanes por la deshonra (abuso sexual) infligida a Julia, una esclavitud moral que va más allá de amarres físicos, lo que humaniza y, de algún modo, singulariza el argumento de esta pieza.

Esta fue estructurada conscientemente en tres actos, aunque, a su vez, puede segmentarse en otros subcódigos, amén de los planteamientos semióticos de Greimas y Bremond. En concreto, se han inventariado 22 funciones en el ACTO I y 19 tanto en el ACTO II, como en el ACTO III. Estas se agrupan en 6 secuencias tanto en el primero como en el segundo y 7, en el tercer acto. Por tanto, como puede verse, el autor ajustó la obra al tiempo de representación, al conferirle cierta homogeneidad estructural y simetría entre sus partes.

Otros de los códigos más importantes son aquellos verbales (extraídos principalmente del diálogo) y no verbales (tomados de acotaciones)

9. Referente histórico: entre 1885-1895 y 1912-1914, unos 150.000 andaluces emigraron a La Plata, Tucumán, Salta, Mendoza, San Juan y Buenos Aires, lugares con un clima similar al andaluz y donde principalmente se dedicaron a labores de horticultura y viticultura.

10. Pedro Luis y Tío Manuel pueden considerarse los heterónimos del autor: el primero, por su carga ideológica; el segundo, por ser testigo de la realidad, testimonio sellado con su única y simbólica intervención: "Pongo mi firma" (López Pinillos, 1918: 13). 
que sirven para la caracterización funcional de los personajes, principal sistema atendido, si comprendemos el drama psicológico. Sin duda, uno de los aciertos mayores, pues las criaturas, lejos de simples estereotipos, son arrancados de la realidad, configurados con gran proyección simbólica y sin caer en simples maniqueísmos: de los once que se listan en el reparto, el protagonismo recae en los tres miembros de la familia Govanes y en el cacique Don Antonio. Concretando más, el dominante, teniendo en cuenta tanto el registro de frecuencias de sus intervenciones como presencias escénicas (criterio cuantitativo), es el progenitor de la familia; el personaje con mayor proyección simbólica (criterio cualitativo) y ese cuya interpretación fue reservada para el director de la compañía ${ }^{11}$, a quien, asimismo, el autor dedicó la obra.

En conclusión, todas las facetas del protagonista traspiran ese pathos sufrido por los héroes trágicos, aunque, en este caso, estemos ante un tipo hastiado y consumido por la ruina económica. Y, además de ser engranaje entre todas realidades y personajes de la obra, Pedro Govanes es el que, por relación metonímica, mejor encarnaría el sentido trágico de todo el pueblo (Sujeto) que sufre el yugo del cacique (Oponente) y que desea, movido por otras fuerzas como el sentido de protección familiar, honor y justicia (Emisor), conseguir la estabilidad-libertad (Objeto). Para ello, necesitaría la fuerza de un Ayudante, que bien podría recaer en Pedro Luis, al encarnar el papel de instigador. De este modo, quedaría resumido el

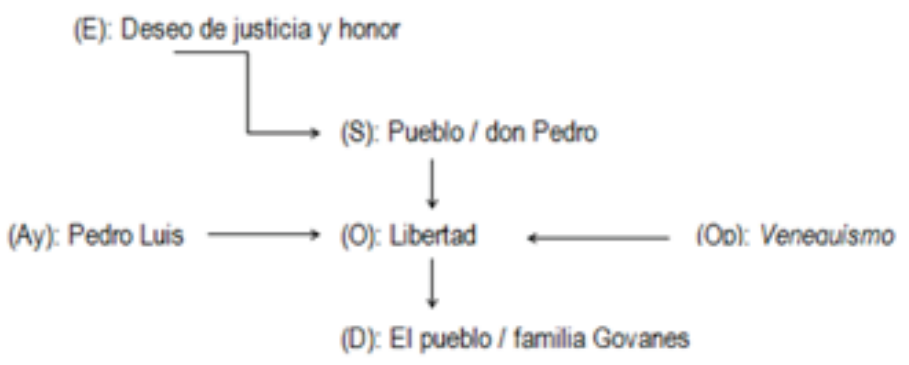

Figura 1. Esquema actancial global del drama Esclavitud.

11. También aparece el elenco de actores que tuvo en cuenta López Pinillos para la interpretación de sus personajes. 
Parmeno se esforzó en ahondar en los caracteres para que el público extrapolase su dimensión simbólica ${ }^{12}$. Asimismo, logró esa tensión psicológica y golpes de efectismo que garantizaron el gusto del respetable mientras aleccionaba catárquicamente: "intenso, fortísimo, de gran teatralidad y, al mismo tiempo, real y educador" (Mori, 1918: 1). Por ello, resultan interesantes tanto las confesiones de los personajes y el habla de cada uno (sociolectos y registros) ${ }^{13}$, como aquellos signos paraverbales (kinésicos, proxémicos y otros de tipo aspectual), que, en suma, son los más reiterados y cuidados. Con esmero y abundantes matices, veló las informaciones gestuales y tonales, dos subcódigos realizados holísticamente como puede verse en el ejemplo siguiente: "Don Antonio. Con tono y gesto agresivo" (López Pinillos, 1918: 56).

También son recurrentes y simbólicos los silencios y pausas, así como el contraste entre los movimientos contenidos y sollozantes de unos (sometidos y femeninos) y los extremadamente violentos y socarrones de los veneguistas. Una atmósfera de tensión conseguida con esporádicos, repentinos y estruendosos recursos sonoros como disparos y golpes, y el debilitamiento paulatino de la luz hasta el apagón final, momento en que el protagonista se hinca de rodillas en actitud suplicante a la Providencia; luz tenue que permite simbólicamente ahondar en lo atrasado, oscuro y asfixiante del espacio.

\subsection{Apuntes sobre la dimensión pragmática}

De acuerdo con la información paratextual de la portada, Esclavitud es un drama "estrenado en el Teatro del Centro el día 28 de Noviembre de 1918”. Tal información, tomada por Awono Onana es, en realidad, errónea, como se puede comprobar rastreando las fuentes periodísticas: se estrenó un lunes 9 de diciembre de 1918.

Efectivamente, aunque el teatro delCentroaúnnohabía experimentado los éxitos de las obras parmenianas, Esclavitud fue la apuesta empresarial

12. Configurada por la onomástica (Ej. Antonio, patrón de los animales; alusión al aspecto endeble de un famoso banderillero de la época con Rojillo...), códigos de vestimenta, peinados, uso de la lengua y demás códigos paralingüísticos. Con ello, también se infiere el lugar que ocupa y función de cada uno dentro del sistema veneguista.

13. Destacan, salvo en el contrapunto de Pedro Luis, los vulgarismos fónicos y morfosintácticos, coloquialismos y refranes, así como animalizaciones despectivas. De hecho, cuanto más arraigado está el personaje en el pueblo (medible por la edad), mayor es la frecuencia de estos recursos, muchos de ellos para reflejar el atraso y analfabetismo. 
para cerrar esa temporada -"El Odeón tiene ya la obra de la temporada" (Machado, 1918: 3)-, al reservar la representación para las 22.00 horas. Tales expectativas venían de los buenos resultados que el género ${ }^{14}$ estaba ofreciendo y éxitos que había cosechado el andaluz durante ese año con tres comedias urbanas. El Odeón no se equivocaba: los triunfos de Esclavitud se tradujeron en notables ingresos y, por ende, en la posibilidad de cerrar ulteriores temporadas con otras creaciones parmenianas: el drama rural $\mathrm{La}$ red (12 de diciembre de 1919) y la comedia urbana Como el humo (30 de diciembre de 1920). Finalmente, y aunque de manera póstuma, también se estrenaría la comedia urbana Los malcasados un 22 de febrero de 1923.

Volviendo a Esclavitud, efectivamente y siguiendo la cartelera, se debió estrenar el 28 de noviembre. Sin embargo, una indisposición del actor que interpretaría a Sacris, retrasó el estreno tal y como se informaba ese mismo 28 de noviembre:

Por enfermedad de Alberto Romea, que hace un papel importantísimo en el drama de "Parmeno" titulado 'Esclavitud', se ha suspendido hasta la semana próxima el estreno anunciado para hoy jueves por la noche ( $L a$ Correspondencia de España, 28 de noviembre de 1918: 4).

Un tipo de información que también nos ayuda a analizar el horizonte de expectativas que suscitaba el estreno:

El lunes, en el teatro del Centro, se estrenará el drama "Esclavitud", original del popular periodista "Parmeno". Hemos presenciado algunos ensayos de la nueva obra y auguramos al redactor del "Heraldo de Madrid" un éxito grande (La Mañana, 7 de diciembre de 1918: 12).

A tenor del último ensayo general, Carretero Novillo publicó en El Fígaro (1918: 11) una crónica donde se revelan datos y apuntes valiosísimos para entender la dramaturgia que se preparaba. Nos permite tomar el pulso de los miedos, intereses y expectativas del dramaturgo y

14. El éxito de los dramas rurales es evidente: sin ir más lejos, el mismo 9 de diciembre se estrenó otro drama rural en el madrileño La Eslava: El Jayón de una debutante Concha Espina de la Serna. 
saber que la dramaturgia fue preparada por el propio autor, quien con su personalidad displicente dispensó exhortaciones ${ }^{15}$ al equipo técnico (doce tramoyistas, carpinteros, pintores, electricistas..., capitaneados por Cirera) y requerimientos escenográficos que consideraba pertinentes a Amorós y Blancas, según la manera que había concebido la obra desde que empezara a redactarla dos meses y medio antes (al terminar la comedia Las alas).

La obsesión del autor fue intentar recrear ese espacio mimético que fuese semánticamente significativo: notar lo asfixiante y frío del espacio representado (galería de la propiedad caciquil). De ahí, su empeño en un decorado señorial, aunque carcomido por el tiempo, y una escasa iluminación escénica, que fuese debilitándose según trascurriese el tiempo diegético hasta el anochecer del tercer acto. Para ello, el dramaturgo confirió una función relevante a una majestuosa lámpara eléctrica -no advertida en el texto literario-, colgada y ubicada en medio del escenario.

El nerviosismo era patente y hasta reconocido por el propio Parmeno. Gracias al testimonio y confesiones de este, debemos imaginarle apasionado; que escribía teatro después de finalizar ocupaciones periodísticas; que prefería la redacción de dramas antes que comedias: "para satisfacción de mi sentimiento artístico" (Carretero Novillo, 1918a: 11); que se emocionaba antes de los estrenos y "más este hecho con todo amor y en el que me juego la reputación, la honra y no me juego dinero, porque cuando yo escribo drama, no escribo para ganar dinero. Para eso están las comedias" (Carretero Novillo, 1918a: 11).

La compañía que ejecutó la performance fue la del catalán Enrique Borrás, conocida por entonces como Gran Compañía Dramática. Esta experimentada agrupación ${ }^{16}$ contaba por entonces ${ }^{17}$ con un elenco de once actores: Pedro Govanes sería interpretado por el director; Julia Govanes, por la actriz Carmen Muñoz; Consolación, Adela Calderón; Natividad, Matilde Llopis; Pedro Luis Govanes, Ramón Gatuellas; Don Antonio Venegas, Ruiz Tatay; Sacris, Alberto Romea; Caramechá, Constante Viñas; Rojillo, José G. Marín; Sisí, José Trescoli, y Tío Manuel, Emilio Piñeira.

La selección del elenco no resultaba baladí en una obra que, como

15. "En un ataque de locura, grita: -¡Ese Vázquez! ¡Pero por María Santísima, aquí falta todo! La lámpara del centro... [...]. Pero esas puertas no son puertas ni son nada" (Carretero Novillo, 1918a: 11).

16. "La más completa de cuantas hoy actúan en España" (Barberán, 1918: 2).

17. El elenco se reduciría en reposiciones posteriores. 
veíamos desde el análisis del texto literario, resultaba más de caracteres que de tramas. Efectivamente, para comprender las presiones psicológicas de las criaturas dramáticas, el autor, ya desde las didascalias, cuidó la caracterización física y se decidió a describirlos con esos regustos picarescos que permitiesen ahondar en su profundidad psicológica y, con la cual arrancar la empatía y conmoción del espectador. Por ello, los códigos de vestuario, maquillaje y peluquería son cruciales para poder llevar a la praxis la dramaturgia parmeniana. Estos detalles, afortunadamente, no pasaron desapercibidos por la crítica: con sus descripciones y aportación de fortuitos documentos visuales de la representación, podemos aproximarnos al lenguaje espectacular de la función.

Una de las pocas fotografías de la representación del estreno (Figura 2) inmortaliza la escenografía sombría del espacio mimético referido. La instantánea fue tomada en un momento de tensión argumental hacia el final del ACTO I, justo cuando el rudo Caramechá desafía con una faca a Don Antonio.

Contamos en el escenario a diez actores (y un pueblerino extra) de los once que encarnan los personajes de la obra: entre los varones, trajes holgados, sombreros ${ }^{18}$ y camisas blancas; y entre las féminas, peinados recogidos y enfundadas en largos vestidos claros. Tanto unos como otros visten ropajes del mundo rural y solo el corte del traje, tipo y alas del sombrero, y actitud represiva desvelan en primera línea del proscenio la presencia de Ruiz Tatay (Don Antonio).

18. Borrás (Don Pedro) no viste sombrero en la escena. De este modo, se diferencia al protagonista del resto, al tiempo que se presenta cierto desamparo simbólico de este. 


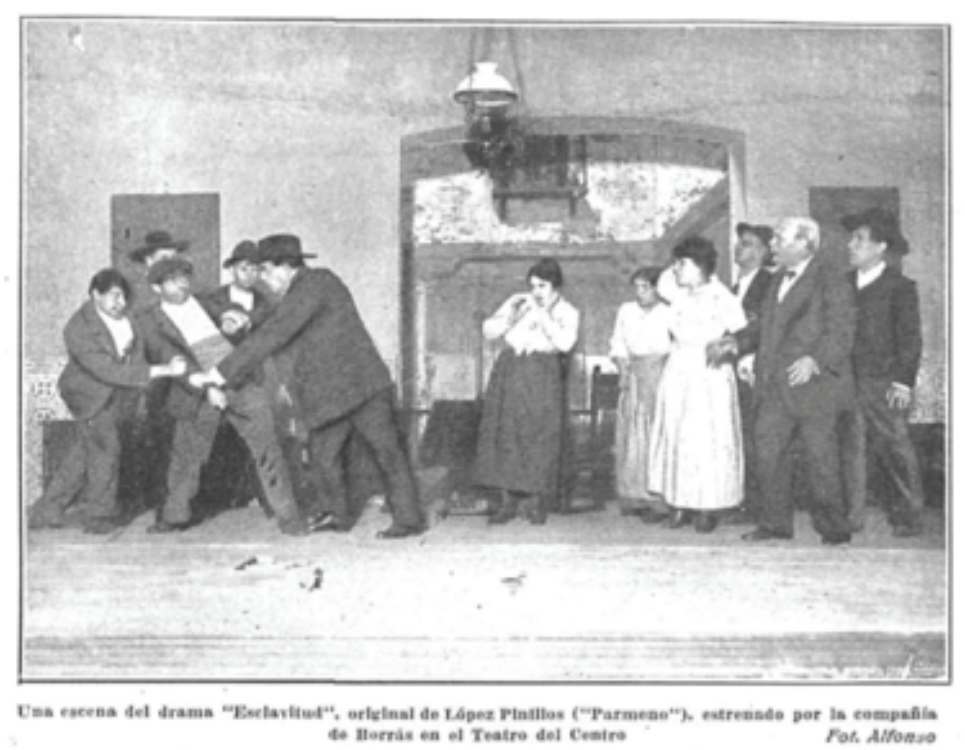

Figura 2. Fotografía de una escena del drama Esclavitud, publicada en Nuevo Mundo (Miquis, 1918a: 14).

No obstante, dos de estas caracterizaciones las adelantaba ya El Fígaro (Carretero Novillo, 1918a: 11) antes del estreno ofreciendo unos esbozos a mano alzada de los perfiles de Carmen Muñoz (Julia) y Enrique Borrás (Don Pedro), cuya caracterización también se puede ver detalladamente en una fotografía a cuerpo completo ofrecida por Nuevo Mundo (Miquis, 1918b: 16).

Finalmente, gracias a una tirada de tres viñetas cómicas que retratan tres momentos representativos de cada acto ${ }^{19}$ publicada tras el estreno ( $A B C$ Madrid, 11 de diciembre de 1918: 6), aprehendemos el estatus y vejez de Sacris; rudeza y cicatrices de Caramechá; vestuario elegante del cacique; lo discordante del peinado y vestuario urbanita de Pedro Luis, y, finalmente, en conjunto, la evolución de Don Pedro quien, según avanza

19. En la primera, se ve a los tres díscolos maniatados (Sacris, Don Pedro y Caramechá); en la segunda, un enfrentamiento entre el cacique y Pedro Luis, y en la tercera, a Julia desvanecida tras la agresión accidental recibida de su padre, socorrida por su hermano y al progenitor arrodillado. 
la obra, se va descamisando y despeinando.

Pero más allá de estos fortuitos documentos visuales, las observaciones críticas también nos ayudan a comprender mejor la dramaturgia, pues son, como reconoce el Caballero audaz, el eco del sentir del público: "yo soy un espectador que habla; y al fin y al cabo, los éxitos y fracasos los dan unos centenares de espectadores reunidos" (Carretero Novillo, 1918b: 15). Por lo general, se detuvieron en la caracterización de los protagonistas. Desde El Fígaro se describió con detallismo la caracterización de Ruiz Tatay:

Tatay pasea ahora por el escenario. Indudablemente él sería el dueño de aquella mansión pueblerina. Su indumentaria de cacique, la gruesa cadena de oro que atraviesa su chaleco y, sobre todo, el crujir de sus flamantes botas negras nos lo dicen. No le falta ni un detalle. El tipo está maravillosamente copiado de la realidad (Carretero Novillo, 1918a: 12).

Más escueta es la descripción de la caracterización de Carmen Muñoz, en parte, por no entonar, según el crítico: "Su busto parece escapado de un retrato antiguo. Nosotros no comprendemos a la Sra. Muñoz nada más vestida de valenciana en un día de fiesta" (Carretero Novillo, 1918a: 12). Pero el actor colmado de atenciones es Enrique Borrás, pues su caracterización fue tal que sorprendió positivamente a la crítica:

Tardamos en reconocerle, porque está admirablemente caracterizado de viejo, con una peluca venerable de cabellos plateados y calva reluciente, gran bigote y la mosca blancos. Sobre los hombros, medio sostiene la capa parda de embozos dorados (Carretero Novillo, 1918a: 12).

Una caracterización que, junto a sus dotes interpretativas y la profundidad literaria del personaje, despertó toda la atención en el estreno de esta función.

Unos dos mil espectadores, entre los que se podían divisar "numerosos políticos y muchos orientadores de multitudes liberales, de las cuales podía decirse que vivía pocas horas muchos años de lucha y 
de miseria" (Mori, 1918: 1) se congregaron tal día en el oscuro Odeón: alojados en el patio de butacas, palcos, entresuelos ${ }^{20} \ldots$ de este céntrico teatro madrileño disfrutaron de un espectáculo que no dejó indiferente a nadie: se glorificó como "el mejor de Pinillos y uno de los mejores entre los modernos" (Laserra, 1918: 3).

Más allá del revuelo que despertara la noticia de una nueva producción del autor, argüimos dos factores que pudieron laurear tanto el estreno como las reposiciones inmediatas: por un lado, se debe tener en cuenta lo genuinamente parmeniano y su implicación en todas las dimensiones del hecho teatral: tanto sus dotes creativas, temperamento, formación y su visión del mundo que se palpa en el texto literario, como el compromiso e implicación del creador en la codificación espectacular de la obra, que se tradujo en el dominio de todos los resortes escénicos. Y, por otra parte, se debe destacar el papel, caracterización e interpretación escénica del actor principal.

Abordemos, en primer lugar, los méritos del autor, a partir de una de las críticas más elogiosas:

Las excelencias literarias de esta nueva producción de "Parmeno" están por encima de todo elogio. [...] Ha vestido "Esclavitud" con las mejores galas, con toda la riqueza que caben en el lenguaje. [...] Domina en absoluto los resortes escénicos (Carretero Novillo, 1918b: 15).

En la obra se cristalizan sus capacidades y aptitudes que venían, por un lado, de su carácter y formación jurista, y, por otro, de las habilidades aprendidas en el taller de experimentación estilística que supuso el periodismo. Todo ello motivó una creación realista, con decididas dosis de simbolismo, efectismo y determinismo naturalista; diálogo vivo, claro, adusto y contundente, y una visión amarga y pesimista de la vida, por el enquistamiento de corruptelas, oligarquías... y por la falta de compromiso y acción de los españoles. Una estética enérgica y sombría (desagradable como el propio autor diagnosticó en reiteradas ocasiones) un poco más atemperada que en otras piezas, ya que esta alejaba a detractores y amigos,

20. La tarifa estándar (entrada y butaca) era de 2.50 pesetas. Lógicamente, gracias a las noticias teatrales publicadas en la prensa de la época, se puede seguir la relación de precios, ofertas y suplementos que ofrecía la empresa, así como los sobreprecios (15\%) si se adquirían en la contaduría. 
quienes se lo venían advirtiendo desde hacía años:

Estas dotes preciadas y precisas, hasta el presente le perjudican por exceso. Tal es mi creencia, y se lo repito una vez más con el firme propósito de contribuir a que se corrija. Endúlcese usted un poco. La vida es muy dura, muy amarga, muy feroz, pero... ino tanto! (Ruiz Contreras, 1950: 159-160).

Cierto es que, como buen observador y medidor de reacciones de sus aciertos y fracasos, López Pinillos redujo las dosis de sordidez, en parte con la caracterización, y función de Pedro Luis; sin embargo, y viéndolo ya desde la semántica del título, Parmeno siguió insistiendo en la intención de que el espectador chapotease en los lodazales de la realidad, para despertar conciencias; en definitiva, sensaciones que esperaba ese público que ya conocía el quehacer dramático del andaluz. Puede verse que es así, si tenemos en cuenta que a ciertos críticos no convenció el personaje del forastero, precisamente por su inverosimilitud:

Un talante falso y acomodadicio a la voluntad del autor [...] desentona del cuadro por la equivocada naturaleza que el autor le dio. Debió encajarlo bajo otra manifestación espiritual y aun social [porque así], hubiera tenido más fuerza emotiva, más propiedad, más naturalidad. [...] Todo en la actuación de este personaje es convencional y artificiosa y pequeña ante la grandeza de otros (Barberán, 1918: 2).

Pese a esta discordancia y al manido recurso dramático final ${ }^{21}$ de la equivocación, el público sintió congoja, aunque tolerada, no de manera masoquista, sino con el respeto que merece el diagnóstico de un cirujano, decidido a extirpar su mal: "inculcan el ejemplo y el público lo santifica" (Mori, 1918: 1). En este sentido, el modo de plasmar la realidad podía

21. Nos referimos a la equivocación de sujeto a quien se agrede: Don Pedro, decidido a eliminar a Don Antonio, hiere con una faca a su hija, al confundirla con este, cuando estaba durmiendo en la habitación del cacique. Efectivamente, este recurso, aunque gustara al público, le resultó decepcionante a J. M. ${ }^{\text {a }}$ Carretero. 
conmover a aquel que entendiese los propósitos de esa "Gente Nueva" regeneracionista; a ese "público inteligente" izquierdista, tal y como se refería el autor al tipo de espectador meta; aunque pudiera resultar una estrategia utilizada a priori con que se excusase de una previsible crítica, significativas resultan las palabras del dramaturgo sobre este respecto y sobre su concepción estética y dramática, publicadas en La Tribuna un día antes del estreno de Esclavitud:

Es posible agradar a un público inteligente, ahondando en las cosas desagradables cuando el escritor-que hurga en la llaga con intenciones de médico y no de verdugo-siente el ambicioso deseo de contribuir a que desaparezcan. Y creo que los que protestan contra todo lo que no sea trivial; que esos sostienen la hedionda majadería de que "al teatro no se va a padecer" -porque confunden la emoción malsana producida por la realidad real con la emoción estética engendrada por la realidad artística-, han estado siempre dominados por la multitud, sana de entendimiento y de corazón, que se afana y se purifica con los bruscos sacudimientos a que la somete el arte dramático. Porque creo en la existencia de ese público, y porque confio en él, me doy el gustazo de escribir -con un desinterés absolutoobras como la que se estrenará mañana (García Antón, 1998: 521).

Por tanto, Parmeno confiaba en que el espectador, sintiéndose identificado con los tipos veristas y las coordenadas espacio-temporales de la trama, aceptase la crítica reivindicativa, vertida desde los escenarios, pues "recorriendo desdichados feudos de la España gris, vale por cien discursos de mitin" (Mori, 1918: 1). Propósitos conseguidos si tenemos en cuenta la ovación que testimonian los medios y los numerosos elogios que recibió por parte de la crítica.

$\mathrm{Y}$ es que, entre los quilates de su obra, se halla el temperamento meticuloso por la obra bien medida, la preocupación por la verosimilitud temática y formal: "corrección en el lenguaje intachable y con un sentido del teatro que destaca sobre muchos autores" (Mori, 1918: 1). Palabras, en definitiva, que reverberan mejor si tenemos en cuenta el panorama 
desolador del que se quejaban algunos críticos como Marín Alcalde, en parte, por la desidia innovadora y la "lamentable decadencia a causa del espíritu complaciente, pusilánime y escéptico [...] que sólo piensa en eludir los riesgos del fracaso" (Marín Alcalde, 1918: 3). Esta sorprendente sequía de genios fue un factor que tuvo en cuenta este crítico para potenciar su elogio a este drama parmeniano:

He aquí, sin embargo, que en medio del páramo se alzan unos cuantos artistas rebeldes dispuestos a reivindicar y a exaltar libremente las naturales características de su temperamento. José López Pinillos [...] es uno de los escasos campeones (Marín Alcalde, 1918: 3).

Sin duda, autor y empresarios brindaron el éxito atronador y, definitivamente, comprendemos mejor los aciertos creativos si traemos a colación la valoración que enuncia José L. Barberán desde el núm. 14.725 de El Globo:

El recio temperamento de "Parmeno", su imaginación de escritor meridional, su altura de hombre estudioso, su nombre de escritor fácil, ameno, fiel narrador de la vida y de los hechos reales, el gran pintor naturalista, consiguió anoche [...] el triunfo señaladísimo, una victoria completa. [...] Horizontes, perspectivas, luces y sombras, tonalidades, perfiles, colorido, todo es asombroso de veracidad y de naturalidad... ni sobra ni falta nada; todo en el cuadro es perfecto. [...] Su pulcritud en el decir, la exposición maestra de los hechos, el acierto en la exposición de las pasiones hondas, bravas, desatadas, apagan esas pequeñas sombras (Barberán, 1918: 2).

Podemos tratar de reconocer cierto magisterio o impronta parmeniana en el panorama teatral madrileño, aunque no debemos obviar que buena parte del mérito de la función debe reconocérsele al popular actor Enrique Borrás. Tanto su caracterización ya comentada, como su excelsa 
interpretación ${ }^{22}$ de la creación del personaje de Don Pedro, catapultaron su carrera y fama:

No acertamos ya a decir, a trascribir la honda emoción e impresión que nos produjo anoche en la interpretación de este nuevo tipo. Caracterización, gesto, ademán, modulaciones e inflexiones de la voz, todo fue nuevo, desconocido para nosotros (Barberán, 1918: 2).

Una interpretación que se tradujo en fuertes y reiteradas ovaciones atronadoras:

El entusiasmo del público llegó anoche hasta el frenesí y, puesto en pie, lo aclamó largamente, hasta enronquecer, llamándole en los mutis con tal insistencia que hubo que parar en dos ocasiones la representación (Barberán, 1918: 2).

Ovaciones que, según continúa el crítico, emocionaron al actor: "Borrás, emocionado, se secaba las lágrimas" (Barberán, 1918: 2). Aplausos y clamores que también recibió Parmeno, quien "al final de los tres actos, se personó en escena" (Barberán, 1918: 2).

Definitivamente, comprendemos que el éxito de Esclavitud vino del compromiso de dos profesionales, completamente implicados en la performance, auténtico y último sentido del drama:

Es un triunfo sólo para los dos; un mismo espíritu fuerte, recio, grande, poderoso, un gran espíritu artístico. No pongas Pinillos y Borrás... No escribas Borrás y Pinillos... Cruza ambos nombres en estrecho abrazo, que el arte es uno y no más, y para el arte es esta labor del autor y del actor... (Barberán, 1918: 2).

22. La interpretación del resto de actores pasó desapercibida: “el conjunto, discreto" (Laserra, 1918: 3); aunque notabilísimo fue el papel de Alberto Romea (Sacris) y Ruiz Tatay (Don Antonio), así como de Carmen Muñoz (Julia) y de Adela Calderón (Consolación) de cuyas dotes interpretativas se dedicaron unas líneas: "sencillez, ternura, de acento, de expresión, de todo, como también Adela Calderón, que su pequeño papel supo hacerlo grande" (Laserra, 1918: 3). 
Es más, podemos aducir que parte deléxito se explica si comprendemos la óptima compenetración entre ambos: contaron recíprocamente con sus talentos y se ayudaron, pues, por un lado, la labor del actor consolidaría la fama del autor y su drama y, por otro, la creación, profundidad y funcionalidad de ese Don Pedro permitiría al actor ${ }^{23}$ experimentar y lucir todas sus dotes interpretativas, gracias a las cuales pudo catapultar su carrera:

Pinillos ha sabido destacar este personaje, acumulando en él belleza extraordinaria, pues aunque no ha de decir nada, porque todo está supeditado al choque entre el fanfarrón tiranoy el arrogante libertador, la atención del público estuvo detenida en este magnífico carácter, tan bien arrancado de la realidad, tan bien visto, tan felizmente trazado... A mi este don Pedro me parece una creación definitiva, que ha de descollar, arrogante como un monumento, en medio de toda la labor teatral de "Parmeno" (Carretero Novillo, 1918b: 15).

$\mathrm{Y}$ es que no pocos actores desearon que el andaluz contara con ellos para interpretar la hondura de sus criaturas y así lucir sus dotes interpretativas. Sin embargo, en este caso, López Pinillos diseñó el papel de Don Pedro pensando en Borrás, con quien ya trabajó en Nuestro enemigo (1913), tal y como reconoce: "Mientras cuente con actores como Borrás, capaces de defenderlas [sus piezas], no me faltará el ímpetu optimista con que las escribo" (García Antón, 1998: 521). Palabras elogiosas y de reconocimiento que quedan definitivamente selladas con la dedicatoria que reza en la obra impresa: “A Enrique Borrás. Gloria y orgullo de la escena, fraternalmente" (López Pinillos, 1918: 7).

\section{CONCLUSIONES}

No cabe duda de que el nombre de José Luis López Pinillos (Parmeno)

23. Borrás, en el discurso pronunciado en el homenaje por los triunfos de la obra en el Hotel Ritz (Madrid), reconoció la oportunidad que López Pinillos le brindó al contar con él para tal interpretación. 
-hoy prácticamente soterrado en los barrizales del olvido, como otros tantos-corresponde a un literato polifacético, comprometido y conocedor de todas las dimensiones que ofrece el artefacto teatral; un temple recio e ideólogo regeneracionista de principios del siglo XX que pretendió con su obra contribuir a la necesaria extirpación de los males que aquejaban las ciudades y campos españoles en tiempos de la Restauración, en pro de esa "España Nueva" vaticinada por regeneracionistas como Joaquín Costa.

Desde los arbitrios cercenadores del paso del tiempo, hay quien enjuicia su obra como una más dentro de un género tan manido como exitoso: el drama rural; sin embargo, nos parece oportuno reconocer la habilidad de Parmeno de saber golpear catárquicamente al público, sin caer en banales moralinas; una fórmula con tintes sociales y reivindicativos arriesgada para los teatros comerciales del momento y que triunfó, sin embargo, al ser pragmático: siempre atento a la crítica, midió hábilmente los aciertos de su estética, contó con buenos actores y se implicó en todos los resortes escénicos.

En el presente artículo hemos ahondado en esas coordenadas contextuales necesarias para poder conocer y enjuiciar con acierto la verdadera contribución dramática del andaluz. Y es que su obra, amén de postulados regeneracionistas e ideas estéticas de regusto naturalista y simbolista, solo puede entenderse comprendiendo sus referentes inmediatos, pues autor y obra son engendros para su tiempo histórico; una perspectiva efímera, si se quiere, pero clave, ya que su producción dramática es totalmente funcional. En este sentido, acercarse a la faceta dramática de J. L. López Pinillos solo a partir del análisis literario de su obra podría desechar el verdadero quehacer polifacético de un autor que estaba casi más implicado en el lenguaje espectacular, que en las diégesis, aunque en ellas también reconocemos un talante literario, sobre todo, en las acotaciones, donde se palpan, bajo un aparente descuido barojiano, gustos picarescos y hasta grotescos al describir mediante cosificaciones e hipérboles caricaturescas, tipos y espacios simbólicamente expresionistas.

El drama rural Esclavitud (1918), a la espera de una obra definitiva que nunca llegaría por el certero golpe de un cáncer pulmonar a sus 42 años, puede erigirse hoy como la pieza teatral paradigmática de Parmeno; para tal condecoración hemos tenido en cuenta las dimensiones analíticas que ofrece el método semiótico y, además del análisis del texto literario, nos hemos detenido en la dimensión pragmática para que puedan comprenderse 
las claves del éxito y sus aportaciones teatrales.

Así, buceando por las secciones teatrales de cabeceras madrileñas de principios de siglo, hemos comprendido mejor tanto las órbitas de la obra (tiempo de composición; expectativas e intenciones; dramaturgia y escenificación, y éxitos, condecoraciones y reposiciones) como la trascendencia de esta dentro de la producción del andaluz (aportación estética, consolidación de sus isotopías en obras posteriores y hasta el reconocimiento de su magisterio). Con Esclavitud, Parmeno se decidió a sellar los que hasta entonces habían sido experimentos literarios y escénicos -visibles en El pantano (1913)-. Al ver ovacionado su sello genuino, en parte gracias a la labor de virtuosos actores como Enrique Borrás, el producto grilló: ahondando en lo desagradable y en la reivindicación social, siguió ofreciéndolo en obras ulteriores como en La red (1919), El condenado (1920) o La tierra (1921), entre otras. No priorizó acciones, sino hondos caracteres veristas y humanos arrancados de lo más sórdido de los abúlicos, rancios y misóginos campos españoles, configurados mediante signos con clara proyección metonímica y simbólica, mediante la cual atizar catárquicamente al espectador.

De este modo, se pueden comprender las respuestas individuales y las auténticas aportaciones de Parmeno en el ruralismo dramático. De hecho, solo desde esta perspectiva, puede valorarse una poética potencial en el ámbito teatral; una aportación catalogada por el propio autor como ruralismo desagradable que va más allá del texto literario, pues se obsesionó porque se codificara bien en el lenguaje espectacular: esa implicación estética e ideológica que traspasa lo diegético es, en suma, la clave de una aportación dramatúrgica que bien se podría sumar a otro aporte parmeniano ya estudiado, el tremendismo narrativo. 


\section{REFERENCIAS BIBLIOGRÁFICAS}

ALMARCHA ROMERO, Á. (2015). “Algunas fuentes periodísticas para el estudio del teatro de Francisco de Viu". Signa. Revista de la Asociación Española de Semiótica 24, 163-178 (también en http://revistas.uned.es/index.php/signa/article/view/14705 [08/04/2017]).

AWONO, D. (2004). El teatro de López Pinillos, "Parmeno". (Tesis doctoral, Universidad de Valladolid). Recuperada de http://www. cervantesvirtual.com/obra/el-teatro-de-lopez-pinillos-parmeno--0/ [08/04/2017].

BARBERÁN, J. L. (1918). "Por los teatros. Impresiones de un espectador". El Globo 14.725, 2 (también en http://hemerotecadigital. bne.es/issue.vm? id $=0001460154 \&$ page $=2 \&$ search $=\&$ lang $=e s$ [08/04/2017]).

BRUN, L. (1919). "Revista teatral". Nuestro Tiempo 241, 80-82 (también en http://hemerotecadigital.bne.es/issue.vm?id $=0002653866 \&$ searc $h=$ \&lang=es [01/04/2017]).

CARICATURA EN EL TEATRO (1918, 11 de diciembre). ABC Madrid, 6 (también en http://hemeroteca.abc.es/nav/Navigate.exe/hemeroteca/ madrid/abc/1918/12/11/006.html [09/04/2017]).

CARRETERO NOVILLO, J. M. ${ }^{a}$ (1918a). "Mirando a la escena. Ensayos interesantes". El Fígaro 116, 11 (también en http://hemerotecadigital.bne.es/issue.vm? id $=0026748253 \&$ search $=\&$ lang $=e s$ [05/04/2017]).

(1918b). "Mirando a la escena. Observaciones de un espectador". El Fígaro 118, 15 (también en http://hemerotecadigital.bne.es/issue.vm ?id $=0026748367 \&$ search $=\&$ lang $=$ es $[05 / 04 / 2017])$.

CASTELLÓN, A. (1994). El teatro como instrumento político en España (1895-1914). Madrid: Endymión.

GARCÍA ANTÓN, A. (1998). "La figura del hijo pródigo en el drama rural de López Pinillos, perspectivas de la rebeldía”. En Estudios de literatura española de los siglos XIX y XX. Homenaje a Juan María Díez Taboada, T. Martínez y G. Antón (coords.), 519-524. Madrid: CSIC.

GUTIÉRREZ FLÓREZ, F. (1989). “Aspectos del análisis semiótico teatral". Castilla: Estudios de Literatura 14, 75-92 (también en https:// dialnet.unirioja.es/servlet/articulo?codigo=136138 [10/04/2017]). 
El Fígaro, 10 (1918). Homenaje a Borrás y López Pinillos. 30 de diciembre. Disponible en línea: http://hemerotecadigital.bne.es/issue.vm?i $d=0026749586 \&$ search $=\&$ lang $=e s[09 / 04 / 2017]$.

La Correspondencia de España, 4 (1918a). Informaciones teatrales. 8 de diciembre. Disponible en: http://hemerotecadigital.bne.es/issue.vm? $i d=0000782391 \&$ search $=$ \&lang $=$ es $[08 / 04 / 2017]$.

La Correspondencia de España, 4 (1918b). Informaciones teatrales, 12 de diciembre. Disponible en: http://hemerotecadigital.bne.es/issue.vm? $i d=0000782647 \&$ search $=\&$ lang $=$ es $[08 / 04 / 2017]$.

La Mañana, 10 (1918). Homenaje a Pinillos y Borrás. 27 de diciembre.

Disponible en línea: http://hemerotecadigital.bne.es/issue.vm?id=0 026344701\&search $=$ \&lang $=$ es [08/04/2017].

LASERRA, J. (1918): "Los teatros". El Imparcial 18.622, 3 (también en http://hemerotecadigital.bne.es/issue.vm?id=0000396596\&search $=$ \&lang $=$ es $[06 / 04 / 2017])$.

LÓPEZ PINILLOS, J. L. (1908). “Adiós, tradición”. Heraldo de Madrid 6.344, 1 (también en http://hemerotecadigital.bne.es/issue.vm? id=0 000563459\&search=\&lang=es [1/04/2017]).

(1918). Esclavitud: drama en tres actos; Las alas: comedia en tres actos, J. Pueyo (ed.). Madrid: Renacimiento (también en https://babel.hathitrust.org/cgi/pt?id=nc01.ark:/13960/ t0bv7r858; view =1 up;seq=184 [1/04/2017]).

MACHADO, M. (1918). “Esclavitud, por J. López Pinillos". El Liberal 14.135, 3 (también en http://hemerotecadigital.bne.es/issue.vm?id= 0001853613\&page $=3 \&$ search $=$ \&lang $=$ es [09/04/2017]).

MAINER, J. C. (2000). Historia, literatura, sociedad (y una coda española), 262-263. Madrid: Biblioteca Nueva.

MARIN ALCALDE, A. (1918). "El teatro". La Acción 1.013, 3 (también en http://hemerotecadigital.bne.es/issue.vm?id $=0003527463 \&$ searc $h=\&$ lang $=$ es $[09 / 04 / 2017])$.

MIQUIS, A. (1918a). "Semana teatral. Tranquilidad, Esclavitud". Nuevo Mundo 1.301, 14 (también en http://hemerotecadigital.bne.es/issue. $v m ?$ id $=0001759069$ \& page $=14$ \& search $=$ \&lang $=e s[09 / 04 / 2017])$. (1918b). "Semana teatral. Esclavitud". Nuevo Mundo 1.302, 16 (también en http://hemerotecadigital.bne.es/issue.vm?id=0001759198\& page $=16 \&$ search $=$ \&lang $=$ es $[09 / 04 / 2017])$.

MORI, A. (1918). "El drama rural". El País 11.105, 1 (también en http:// 
hemerotecadigital.bne.es/issue.vm?id $=0002563603 \&$ search $=\&$ lan $g=e s[09 / 04 / 2017])$.

Noticias e informaciones teatrales (1918, 28 de noviembre). La Correspondencia de España, 4 (también en http://hemerotecadigital.bne. es/issue.vm?id=0000781797\&search=\&lang=es [10/04/2017]).

OLIVA, C. (2001). "Teatro y sociedad en la España del siglo XX". En Literatura y sociedad: el papel de la literatura en el siglo $X X, \mathrm{~F}$. López Criado (ed.), 77-96. A Coruña: Universidad da Coruña.

PEDRAZA JIMÉNEZ, F. B. (2011). El drama rural: metamorfosis de un género: la perspectiva española y el contexto internacional. Pontevedra: Academia del Hispanismo (Biblioteca de Theatralia).

PRATS MARTÍN, S. (2016). Una nueva mirada al teatro de J. Luis López Pinillos ("Parmeno"). Análisis del drama "Esclavitud" (1918). (Master Thesis, Universidad Nacional de Educación a Distancia). Recuperada de http://e-spacio.uned.es/fez/view/bibliuned:masterFilologia-FILTCE-Sprats [08/04/2017].

RUIZ CONTRERAS, L. (1950). Día tras día (Correspondencia particular: 1908-1922). Madrid: Aguilar.

SITO ALBA, M. (1987). Análisis de la semiótica teatral. Madrid: UNED.

TEATROS (1918, 5 de diciembre). La Mañana, 5 (también en http:// hemerotecadigital.bne.es/issue.vm?id $=0026344068 \&$ search $=\&$ lan $g=e s[08 / 04 / 2017])$.

TEATROS (1918, 7 de diciembre). La Mañana, 12 (también en http:// hemerotecadigital.bne.es/issue.vm? id $=0026344130 \&$ search $=\& l a n$ $g=e s[08 / 04 / 2017])$.

TORDERA SÁEZ, A. (1980). “Teoría y técnica del análisis teatral”. En Elementos para una semiótica del texto artístico (poesía, narrativa, teatro, cine), J. Taléns, J. Romera Castillo et. al., 157-199. Madrid: Cátedra (Crítica y estudios literarios).

Recibido el 11 de abril de 2017.

Aceptado el 16 de junio de 2017. 
